\title{
IMPROVING ENGINEERING EDUCATION: TWO KEY AREAS TO FOCUS OUR ATTENTION
}

\author{
Nancy Nelson, Robert Brennan \\ Schulich School of Engineering, University of Calgary \\ nancy.nelson1@ucalgary.ca rbrennan@ucalgary.ca
}

\begin{abstract}
Engineering remains one of the most traditional and didactic disciplines in higher education. There is low adoption of research-based instructional practices with many educators believing adherence to tried-and-true methods in undergraduate engineering programs outweigh the benefits any change to more active learning could bring. Surveys of student engagement consistently rank the effectiveness of the undergraduate engineering experience lowest among the disciplines, with classroom observations confirming that engineering educators score significantly lower in delivery, teaching, lesson elements, and diversity.

This quantitative study sets out to determine in which, if any, specific areas engineering educators score differently than their colleagues in other disciplines. Using Draeger and his team's model of academic rigour as a framework, this study examines institutional data collected during three years of mandatory teaching observations of new full-time and randomly selected parttime educators.

The analysis shows that four key areas differentiate the teaching practices of engineering educators from their colleagues in other disciplines: (1) welcoming students, (2) explaining the lesson's agenda, (3) the organization, pace, and planning of classes, and (4) the way material is presented to students.

It is proposed that the undergraduate engineering experience can be improved by making changes to lesson structure, and enhanced by including opportunities for meaningful active learning.
\end{abstract}

Keywords: engineering education; teaching practices; active learning; novice; educational development; professional development

\section{INTRODUCTION}

Student engagement studies continue to show that engineering educators rank lowest among their peers in other undergraduate disciplines. Engineering classes remain content-focused with lecturing as the preferred method of delivery.
Previous work reported the results of a mixed method analysis of mandatory observations of novice postsecondary educators. It confirmed the findings that educators in engineering-related disciplines (novice or otherwise) ranked significantly lower than all other disciplines in four distinct areas: lesson elements, delivery, quality of teaching, and diversity. The goal of this study is to determine which, if any, of the specific criteria within each of these four areas are contributing to the low ranking of the engineering education experience.

\section{BACKGROUND}

Myriad studies show that post-secondary Science, Technology, Engineering and Mathematics (STEM) educators are reluctant to move from traditional teaching practices to those that include research-based instructional strategies (RBIS). In an effort to preserve academic rigour, didactic practices often translate to a less than engaging experience for undergraduate engineering students. This section examines the literature on STEM teaching practices, perceptions of student engagement, and academic rigour.

Engineering remains one of the most traditional and didactic disciplines in higher education [1] despite extensive research showing that both learning and student engagement improve with a more active approach [2][3][4]. Most classes remain lecture-based with a few non-rhetorical questions sprinkled throughout [5]. Students listen and may take notes, but they are only sporadically involved in their learning. Some educators choose a more interactive lecture style by supplementing direct instruction with group and/or clicker-type activities, but fewer than $20 \%$ incorporate student-centered instructional strategies into more than a small part of their classes [1].

This low adoption of research-based instructional practices is common across Science, Technology, Engineering, and Mathematics (STEM) disciplines [6]. Henderson and his colleagues report that, while the majority of STEM educators have knowledge of, and have tried, at least some research-based strategies, many return to their more traditional, didactic practices [7][8] 
[9]. This may be attributed to an ingrained belief that adherence to tried-and-true methods in undergraduate engineering programs outweighs the benefits any change to more active learning might bring about [10].

Surveys of student engagement consistently rank the effectiveness of the undergraduate engineering experience lowest among the disciplines [11][12][13][14]. Engineering students perceive their engagement lowest in the benchmarks associated with learning strategies, effective teaching practices, quality of interactions, and supportive environment [15], while their faculty show the lowest rankings in the areas of learning strategies, discussion with diverse others, effective teaching practices, and supportive environment [16]. These four common benchmarks suggest there is room for improvement in the teaching practices of undergraduate engineering educators.

A study of classroom observations of novice educators confirms that engineering educators score significantly lower than their colleagues in other disciplines in four similar areas: (1) classroom delivery, (2) teaching practices, (3) lesson elements, and (4). diversity [16]. It finds that there is little difference in the teaching practices of novice engineering educators from those of their more experienced colleagues, and recommends disciplinespecific educational development focusing on researchbased instructional strategies that enhance student engagement while maintaining academic rigour.

Post-secondary educators report many barriers that impede their transition to more active classrooms. These include, but are not limited to, classroom design, class size, ill-prepared students, and the time required to prepare the course [10]. STEM educators ranked these barriers higher than all other disciplines and showed the highest positive difference for the barrier, "Active learning takes too much class time causing the coverage of content to suffer". Educators often equate content coverage with academic rigour, interpreted as "academically, intellectually, and personally challenging instruction and learning experiences" [17]. Draeger and his colleagues suggest a model for academic rigour that addresses the challenges associated with shifting toward student-centred teaching practices [18]. It describes academic rigour as "actively learning meaningful content with higher-order thinking at the appropriate level of expectation within a given context". It is through this lens that this research seeks to extend the study of classroom observations in order to answer the following question: Are there specific aspects of observed lesson elements, classroom delivery, teaching practices, and diversity that differentiate engineering educators from their colleagues in other schools/disciplines?

\section{METHODOLOGY}

This study examined a subset of the institutional data collected during four semesters of mandatory teaching observations of new full-time faculty members and randomly selected part-time instructors at a large polytechnic school. Classes were observed for approximately one hour with an intent to provide insights into the educator's strengths and potential areas for teaching-related development. Observations were done mid-way through the term by one of 20 trained observers who was either a full-time Education Developer or a retired professor recognized for their evidence-based teaching practices. Faculty members were asked to provide digital copies of their lesson plans, course outlines and any other resources that would be used during the class.

Each observed faculty member, whether full- or parttime, is required to attend a series of five mandatory workshops before or during their first term of teaching. These workshops orient new educators to the institutional expectations related to teaching, assessment, creating a positive learning environment, and using the Learning Management System (LMS). The final workshop informs faculty members of the services available to support both their students and themselves.

The observation instrument was aligned with the institution's Student Assessment of Teaching (SAT) and had been validated over many years. It included 65 threelevel (yes / somewhat / no) Likert scale questions that focused on six main areas: (1) lesson elements (21 questions), (2) clarity and subject matter expertise (SME) (six questions), (3) delivery skills, enthusiasm, and rapport (nine questions), (4) teaching skills (16 questions), (5) diversity, inclusion, and accessibility (10 questions), and (6) legal obligations (three questions). Observers had the option of adding an explanatory comment to each response. Observers also specified three observed strategies that support student learning, and three opportunities to enhance practice as a professional educator. A digital copy of the observation instrument was shared with faculty prior to the scheduled observation.

Each educator received a digital observation report approximately one week after the observation. They were asked to review the report and submit their reflections prior to a one hour coaching session. The process ended when the report and instructor reflections were sent to the instructor's department head.

\subsection{Data Analysis}

585 developmental teaching observations were performed over four teaching terms starting in September 2018 and ending in December 2019. 571 of these reports were complete $(97.6 \%)$ and are included in this analysis. Table 1 shows the number and percentage of observations 
from each discipline. Most of the 571 educators were part-time employees $(83.2 \%)$ with the remaining $16.8 \%$ being full-time faculty members in their first semester of teaching.

All 65 questions from the observation instrument were included in the analysis. Responses were reported as numerical codes with 'Yes' as 4, 'Somewhat' as 3, and 'No' as 2. Any 'Not Applicable' (N/A) responses were coded as 1. A Kruskal-Wallis $\mathrm{H}$ test was performed to identify any questions that had a significant difference between the educators in different disciplines. MannWhitney $U$ tests were then performed for each of those questions to identify all significant differences between the scores of engineering faculty and those in other disciplines.

Table 1: Number of Observations by Discipline

\begin{tabular}{|l|c|c|}
\hline Discipline & $\begin{array}{c}\text { Number of } \\
\text { Observations } \\
\text { (PT/FT) }\end{array}$ & $\begin{array}{c}\text { Percentage } \\
\text { of } \\
\text { Observations }\end{array}$ \\
\hline Humanities & $45(44 / 1)$ & $7.9 \%$ \\
\hline Business & $194(165 / 28)$ & $34.0 \%$ \\
\hline $\begin{array}{l}\text { Communications, } \\
\text { Media \& Public } \\
\text { Relations (CM\&PR) }\end{array}$ & $103(85 / 11)$ & $18.0 \%$ \\
\hline Engineering & $104(79 / 21)$ & $18.2 \%$ \\
\hline Health & $28(20 / 7)$ & $4.9 \%$ \\
\hline Social Services & $29(22 / 7)$ & $5.1 \%$ \\
\hline Other & $68(49 / 19)$ & $11.9 \%$ \\
\hline count: & $571(464 / 94)$ & \\
\hline
\end{tabular}

\section{RESULTS}

The Kruskal-Wallis $H$ test showed that there were statistically significant differences between the different disciplines in 12 of the 65 items measured: three from lesson elements (LE), two from delivery skills, enthusiasm, and rapport (DER), four from teaching skills (TS), one from diversity, inclusion, and accessibility (DIA), and two from legal obligations (LO). $\mathrm{H}$ test results for these 12 items are summarized in Table 2.

Follow-up Mann-Whitney $U$ tests identified 28 significant differences between the scores of engineering faculty and those in other disciplines. Table 3 shows the mean $(\mu)$ and two-tailed significance (p) for each significant difference. Relationships with no significance difference are marked with '---'. Each result can be interpreted as follows: The scores of engineering educators on question LE - A3 $(\mu=3.66)$ were lower than those in humanities $(\mu=3.89, p=0.009)$, or the scores of engineering educators on question TS - D5 $(\mu=$ 3.66) were higher than those in humanities $(\mu=1.43, \mathrm{p}=$ $0.003)$.
Table 2: Kruskal-Wallis H Test Results

\begin{tabular}{|l|c|c|}
\hline Question & $\chi 2(6)$ & $\mathrm{p}$ \\
\hline LE - A3 & 27.756 & 0.010 \\
\hline LE - A4 & 15.425 & 0.017 \\
\hline LE - A11 & 26.756 & $<0.001$ \\
\hline DER - C2 & 20.547 & 0.002 \\
\hline DER - C4 & 14.598 & 0.024 \\
\hline TS - D2 & 13.073 & 0.042 \\
\hline TS - D5 & 15.805 & 0.015 \\
\hline TS - D9 & 16.203 & 0.013 \\
\hline TS - D10 & 12.609 & 0.050 \\
\hline DIA - E1 & 15.903 & 0.014 \\
\hline LO - F2 & 17.850 & 0.007 \\
\hline LO - F3 & 14.792 & 0.022 \\
\hline
\end{tabular}

Only questions in which engineering educators scored significantly higher or lower than their colleagues in four or more of the six other disciplines will be considered aspects of concern. These questions are highlighted in the table and the questions are worded as: (LE - A3) students welcomed, (LE - A4) agenda on board and explained, (LE - A11) organized, well-paced, and well-planned, and (TS - D9) provided pauses, transitions and sectioning to aid comprehension, note-taking, and attention.

\section{DISCUSSION}

The results of this study offer unique insights into the teaching practices of early career educators as reported by educational developers and experienced educators. The analysis, viewed through the lens of academic rigour, highlights two key findings:

1. the undergraduate engineering experience could be enriched by using an evidence-based lesson planning tool to section and pace content

2. student comprehension and attention could be enhanced by including opportunities for meaningful active learning

It is understandable that early-career engineering educators choose to adhere to traditional and didactic teaching practices, with most novice educators teaching the way they were taught. Darling-Hammond calls this the apprenticeship of observation, where new instructors believe teaching is the transfer of information [19]. Engineering is considered to be a content-heavy discipline, with students reporting that it is often difficult to keep up with the pace at which classes are conducted [20]. 
Table 3: Mann-Whitney U Test Results

\begin{tabular}{|c|c|c|c|c|c|c|c|}
\hline Question & $\begin{array}{c}\text { Engineering } \\
(\mu)\end{array}$ & $\begin{array}{l}\text { Humanities } \\
(\mu, p)\end{array}$ & $\begin{array}{c}\text { Business } \\
(\mu, p)\end{array}$ & $\begin{array}{c}\text { CM\&PR } \\
(\mu, p)\end{array}$ & $\begin{array}{l}\text { Health } \\
(\mu, p)\end{array}$ & $\begin{array}{c}\text { Social } \\
\text { Services } \\
(\mu, p)\end{array}$ & $\begin{array}{l}\text { Other } \\
(\mu, p)\end{array}$ \\
\hline LE - A3 & 3.66 & --- & $3.85,0.009$ & --- & $3.93,0.047$ & $4.00,0.011$ & $3.88,0.014$ \\
\hline $\mathrm{LE}-\mathrm{A} 4$ & 3.08 & $3.43,0.032$ & $3.35,0.016$ & $3.53,0.000$ & $3.57,0.022$ & --- & --- \\
\hline $\mathrm{LE}-\mathrm{A} 11$ & 3.60 & $3.77,0.009$ & $3.80,0.000$ & $3.71,0.039$ & --- & $3.93,0.002$ & $3.88,0.000$ \\
\hline DER - C2 & 3.20 & --- & --- & --- & $3.50,0.030$ & $3.86,0.000$ & --- \\
\hline DER - C4 & 3.34 & --- & --- & --- & $3.71,0.039$ & --- & --- \\
\hline $\mathrm{TS}-\mathrm{D} 2$ & 2.94 & --- & $3.28,0.007$ & --- & $3.50,0.002$ & --- & --- \\
\hline TS - D5 & 2.27 & $1.43,0.003$ & & $1.80,0.043$ & --- & --- & --- \\
\hline TS - D9 & 3.26 & $3.50,0.030$ & $3.43,0.027$ & $3.50,0.002$ & --- & $3.69,0.004$ & --- \\
\hline TS - D10 & 3.51 & $3.89,0.001$ & --- & --- & --- & --- & --- \\
\hline DIA - E1 & 3.23 & --- & --- & --- & $3.71,0.005$ & $3.76,0.000$ & --- \\
\hline $\mathrm{LO}-\mathrm{F} 2$ & 3.18 & --- & --- & --- & --- & $3.14,0.007$ & --- \\
\hline $\mathrm{LO}-\mathrm{F} 3$ & 4.00 & --- & --- & --- & --- & --- & --- \\
\hline
\end{tabular}

Content is only one aspect of academic rigour. Ideally, classes should have students actively engaged in learning the most meaningful, context-specific aspects of the content. Learning activities should challenge students to apply higher-order thinking skills in order to reach the expected level of achievement [18]. Pedagogy-driven lesson planning models can help educators design classes that emphasize organized, interactive and outcomes-based learning (BOPPPS [21], CLAASS [22]). The structure provided by these models encourages educators to start by welcoming the class and capturing the learners' attention, identifying the intended outcomes or agenda for the session, and assessing the students' prior knowledge. Classes then move into a participatory format that includes presentation of new content interwoven with opportunities for students to apply what they're learning. Classes conclude with a formal or informal measure of acquired knowledge and/or skill and a summary of the key takeaways from the session.

It may be useful to apply the cognitive apprenticeship model during the participatory phase of undergraduate engineering classes [23]. Its intent is to make the thinking and processes associated with a new concept or skill visible to the learners. This three-stage process starts with the instructor modeling or performing a task for the students. Students try the task with the instructor on-hand to coach and provide scaffolding as required. Students are then asked to articulate their thinking and compare it to what's expected. Finally, students practice solving problems on their own. The instructor cycles through this process during a class, gradually increasing the complexity of the task until students are at the expected level of rigour.

This instructional strategy helps manage the cognitive overload that many engineering students experience during content-driven, fast-pace classes [20]. Sweller and his colleagues recommend three techniques that help students manage their capacity to learn [24]: (1) breaking tasks into smaller chunks and clearly demonstrating each step or process associated with the concept or skills, (2) reducing the amount of content by identifying and focusing on the key concepts and minimizing those that are not critical, and (3) using scaffolding to support student learning as they work through increasingly complex applications of the new content.

Academic rigour is enhanced through opportunities for meaningful active learning. The instructional strategies used to address the challenges students experience with content-driven, fast-paced classes are a step in the right direction, but there are other ways that engineering educators can increase rigour through active learning. The PODS-FC framework provides faculty with a simple way to remember six key, evidence-based factors when developing classes that integrate active learning [25].

$\mathrm{P}$ stands for the Percentage of time spent lecturing, compared to the time allocated to active learning. It is recommended that $20-60 \%$ of class time be dedicated to transmission of knowledge, leaving $40-80 \%$ for learners to meaningfully engage with the content [26].

$\mathrm{O}$ stands for Outcomes. It is important that educators are clear about what the intended learning outcomes are for each class. They need to recognize what it means for students to master the content and choose activities that enable students to achieve at the expected level.[27].

$\mathrm{D}$ represents what the learners will Do during class. Surface learning often occurs when a class emphasizes content coverage, so choosing activities that focus on the underlying meaning, principles and context-specific applications will help students see value in what they're 
learning and motivate them to use deeper learning strategies [28].

S stands for 15-20 minute $\underline{\text { Segments which encourage }}$ use of the cognitive apprenticeship model to give learners the opportunity to actively engage with each level of complexity as it is delivered [23].

$\mathrm{F}$ represents Flow with variety and suggests that students are more engaged if there is a natural flow during the development of the concept, and there are different type of learning activities through which students engage both lower and higher order thinking skills to acquire the required knowledge and skills [27].

The final factor in the PODS-FC framework is Clarity. Student motivation is enhanced in classes that are organized, have clear goals and provide ongoing feedback on the learners' progress. This helps heighten students' self-efficacy and realize their expectation of success [27].

Applying any, or all, of these PODS-FC factors in the undergraduate engineering classroom will help provide a learning environment in which educators can maintain academic rigour while learners are "actively learning meaningful content with higher-order thinking at the appropriate level of expectation within a given context" [18].

There is a possibility that the findings of this survey have a bias associated with observation. Those observers who were familiar with the subject-matter content may have reported different views from those who did not, even though they were provided with initial training. It is also not known what other factors may have contributed to the observers' responses. The ratio of full- to part-time faculty may also introduce a bias. New full-time faculty are limited in the number of courses they teach during their first year of employment, their first year, but parttime faculty are not. Finally, this data was collected to provide developmental feedback to those being observed, and not specifically for this analysis. Each of these may limit the generality of the results of this study. As a result, the findings should be considered in the context of the limitations of this study.

\section{CONCLUSIONS AND FUTURE WORK}

This research supports and extends the findings of myriad studies that report that undergraduate engineering students have a less effective experience than those of their peers in other disciplines. This study identifies that the learning experience could be enriched by making changes to the structure and pace of classes, and by including more opportunities for meaningful active learning within each class. These changes do not threaten the academic rigour of the course and/or program; instead they establish a learning environment that motivates students to apply deep learning strategies which lead to better mastery of the discipline-specific knowledge and skills required to move from doing engineering things to becoming and thinking like an engineer.

This research lays the foundation for further study. Work could be done to examine the effect that disciplinespecific educational development has on teaching practices and academic rigour. These development opportunities could inform, educate, encourage, and support educators as they plan for and integrate meaningful active learning into the undergraduate engineering experience.

It is hoped that adding the findings of this research to the existing body of evidence on engineering educators' teaching practices will encourage engineering educators, and those responsible for their educational development, to recognize the need for discipline-specific opportunities to explore pedagogically-sound instructional strategies that balance academic rigour with deep student learning.

\section{Acknowledgements}

This research study is funded by the National Sciences and Engineering Research Council of Canada (NSERC) and approved by the Conestoga College Research Ethics Board. Special thanks to the peer reviewers for their time and invaluable feedback.

\section{References}

[1] M. Stains et al., "Anatomy of STEM teaching in North American universities," Science, vol. 359, no. 6383. 2018.

[2] S. Freeman et al., "Active learning increases student performance in science, engineering, and mathematics," Proc. Natl. Acad. Sci., vol. 111, no. 23, pp. 8410-8415, 2014.

[3] D. C. Haak, J. HilleRisLambers, E. Pitre, and S. Freeman, "Increased Structure and Active Learning Reduce the Achievement Gap in Introductory Biology," Science (80-. )., vol. 332, no. 6034, pp. 1213-1216, 2011.

[4] T. J. Shaw, S. Yang, T. R. Nash, R. M. Pigg, and J. M. Grim, "Knowing is half the battle: Assessments of both student perception and performance are necessary to successfully evaluate curricular transformation," PLoS One, vol. 14(1): e02, 2019.

[5] N. Nelson and R. Brennan, "Snapshot of engineering education in Canada," CEEA Conf. Proc. 2018, pp. 110, 2018.

[6] S. Laursen, "Levers for change: An assessment of progress on changing STEM instruction," 2019.

[7] C. Henderson, M. Dancy, and M. NiewiadomskaBugaj, "Use of research-based instructional strategies in introductory physics: Where do faculty leave the innovation-decision process?," Phys. Rev. ST Phys. Educ. Res., vol. 8, no. 020104, 2012.

[8] J. E. Froyd, M. Borrego, S. Cutler, C. Henderson, and M. J. Prince, "Estimates of use of research-based instructional strategies in core electrical or computer engineering courses," IEEE Trans. Educ., vol. 56, no. 4, pp. 393-399, 2013. 
[9] S. Cutler, M. Borrego, V. Tech, C. Henderson, and J. Froyd, "A Comparison of Electrical, Computer, and Chemical Engineering Facultys ' Progressions through the Innovation-Decision Process," in Frontiers in Education, 2012, p. 5.

[10] J. Allen, "Faculty Approaches to Active Learning: Barriers , Affordances and Adoption," Georgia State University, 2018.

[11] National Survey of Student Engagement, "Engagement Insights: Survey Findings on the Quality of Undergraduate Education - Annual Results 2018," 2018.

[12] Quality Indicators for Learning and Teaching, "2017 Student Experience Survey: National Report," 2017.

[13] UNISTATS, "The National Student Survey (NSS)," 2018. [Online]. Available: https://unistats.ac.uk/findout-more/National-Student-Survey-(NSS). [Accessed: 28-Jan-2019].

[14] Faculty Survey of Student Engagement, "FSSE 2018 Aggregate Scales," 2018.

[15] N. Nelson and R. Brennan, "Effective Learning Environments: Is there alignment between the ideal, the actual, and the students' perspective?," in CEEA Conference Proceedings 2019, 2019, p. 7.

[16] N. Nelson and R. Brennan, "A Comparison of the Teaching Practices of Novice Educators in Engineering and Other Post-Secondary Disciplines," in CEEA Conference Proceedings 2020, 2020.

[17]. Great Schools Partnership, "Rigor," The Glossary of Educational Reform, 2014. [Online]. Available: https://www.edglossary.org/rigor/.

[18] J. Draeger, P. del Prado Hill, L. R. Hunter, and R. Mahler, "The Anatomy of Academic Rigor: The Story of One Institutional Journey," Innov. High. Educ., vol. 38, no. 4, pp. 267-279, 2013.

[19] L. Darling-Hammond, Powerful teacher education: Lessons from exemplary programs. San Francisco, CA: Jossey-Bass, 2006.

[20] N. Nelson and R. Brennan, 'Engineering students' perceptions of the learning experience and its impact on student success," in REES Conference Proceedings 2019, 2019, p. 9.

[21] P. Fenrich and R. Johnson, "Instructional Skills Workshops: A model for training professors how to teach," Res. Highlights Educ. Sci., 2016.

[22] Carleton EDC, "Lesson Planning," Teaching Resources Blog, 2017. [Online]. Available: https://carleton.ca/edc/teachingresources/coursedesign/lesson-planning/. [Accessed: 12-Feb-2021].

[23] A. Collins, J. Seely Brown, and A. Holum, "Cognitive Apprenticeship: making thinking visible," Am. Educ., vol. Winter, 1991.

[24] J. Sweller, P. Ayres, and S. Kalyuga, Cognitive Load Theory, 1st ed. New York, NY: Springer, 2011.

[25] N. Nelson, "Best Practices for Remote Delivery," presented during faculty workshop, Conestoga College, Kitchener, ON, May 5, 2020. [Online]. Available: https://www.youtube.com/watch_popup?v=LGX_FDD Jmr4. [Accessed: 13-Feb-2021].

[26] C. Henderson, R. Khan, and M. Dancy, "Will my student evaluations decrease if I adopt an active learning instructional strategy? What do we know about student evaluations as a measure of teaching quality?," Am. J. Phys., pp. 1-19.

[27] J. Biggs and C. Tang, Teaching for Quality Learning at University: What the Student Does, 4th ed. New York, NY: Open University Press, 2011.

[28] K. Trigwell and M. Prosser, "Improving the quality of student learning: the influence of learning context and student approaches to learning on learning outcomes," High. Educ., vol. 22, pp. 251-266, 1991. 